\title{
Migração: a amarga vida de canavieiro do camponês do Semiárido ${ }^{1}$
}

Cícero Ferreira de Albuquerque ${ }^{2}$ Márcio de Matos Canielo ${ }^{3}$

Resumo: $\mathrm{O}$ fenômeno em tela é o da migração cíclica. A vida em pequenas e médias propriedades exige a migração. Ela é uma estratégia de pecúlio das famílias camponesas e serve ao seu projeto de reprodução. Mesmo enfrentando durante o período migrado condições adversas de existência e relações de trabalho de assalariamento, sua condição camponesa não é negada, o camponês não é reduzido à condição de proletário. Fatores macroeconômicos são decisivos para que a migração aconteça, mas também não podem ser negligenciados eventos conjunturais como a seca, por exemplo, ou mesmo acontecimentos culturais como a tradição de migrar constituída no seio das famílias camponesas.

Palavras-chave: Migração, camponês, seca, trabalho.

Abstract: The phenomenon in question it's the cyclical migration. Life in small and medium farms require migration. It is an annuity strategy of rural families and serve to their reproduction project. Even facing during the migrated period adverse conditions of existence and labor relations of remuneration their peasant condition is not denied, the peasant is not reduced to the condition of the proletarian. Macroeconomic factors are decisive for the migration to happen, but It

1 Versão ampliada e reintitulada de comunicação originalmente apresentada no GT “Trabalho agrícola, migração sazonal e mudanças tecnológicas na agricultura", do5 o Encontro da Rede de Estudos Rurais (Belém-PA, 03 a 06/Jun/ 2012).

2 Doutorando em Ciências Sociais pela Universidade Federal de Campina Grande (UFCG). Bolsista CAPES-DS. Colíder do Grupo de Pesquisa/CNPq Trabalho e capitalismo contemporâneo e membro do GP Desenvolvimento sustentável do Semiárido. Membro da Rede de Pesquisadores e do Núcleo de Estudos do Semiárido (PET Nesal). Professor da Universidade Federal de Alagoas (UFAL) - Campus Arapiraca - Unidade Palmeira dos Índios. Email: cicerofalbuquerque@hotmail.com.

${ }^{3}$ Doutor em Sociologia pela Universidade Federal de Pernambuco (2001). Desde 1986 é Professor Associado de Antropologia da Universidade Federal de Campina Grande (UFCG). Líder dos GP's/CNPq: Desenvolvimento sustentável do Semiárido e Análise de desempenho em Políticas Públicas. Coordenador do Projeto Universidade Camponesa (UNICAMPO). Email: marciocaniello@gmail.com.

Latitude, vol. 5, no 1, pp. 113-131, 2011

DOI: https://doi.org/10.28998/2179-5428.20110105 


\section{Migração: a amarga vida de canavieiro do camponês do Semiárido ${ }^{1}$}

can not be neglected conjunctural events such as drought, for example, or even cultural events as the tradition of moving up within the peasant families.

Keywords: Migration, peasant, dry, work.

\section{1- Introdução}

O objetivo deste artigo é analisar a migração temporária do camponês do Semiárido para a região canavieira e o recrudescimento das condições de trabalho nos canaviais de Alagoas, fenômeno igualmente observado em outras regiões do país.

A imagem do retirante da seca no Nordeste é recorrente na literatura brasileira. A descrição pormenorizada da terra seca e do sofrimento do homem do Semiárido corre o mundo em Vidas Secas, de Graciliano Ramos. Em Morte e vida Severina, o retirante de João Cabral de Melo Neto, fugindo da seca, atravessa a região canavieira e descobre na grande cidade um universo ainda mais adverso do que aquele que deixara para trás. No entanto, foi Os sertões, documentário de Euclides da Cunha, a obra que mais destacou o Sertão e as agruras da seca para o Brasil e para o mundo. Na literatura especializada também encontramos um grande destaque para a seca como um fenômeno característico da região sertaneja. Em A terra e o homem no Nordeste, Manuel Correia de Andrade (1998, p. 46), afirma que "O sertanejo está sempre preocupado com a seca, já que desde os tempos coloniais ela vem se repetindo, com maior ou menor intensidade, mas com periodicidade impressionante".

O sertanejo não migra porque é fraco e foge de sua realidade. Em Vidas Secas, Ramos nos diz que do Sertão migram homens fortes, brutos e migram levando consigo sonhos de uma vida melhor. Quando a migração é temporária, o sertanejo é mobilizado por ideais que o seguem e por ideais que ele deixa no Sertão. A migração periódica não é um fim, mas um meio. O sertanejo chega ao corte da cana procurando meios para sustentar a sua família no período seco, mas também engajado num projeto de manutenção e melhoramento de sua terra. Esse sentido estratégico da migração campesina escapa a muitos observadores, mas é fundamental para entender não só o deslocamento sazonal, como também o próprio comportamento do migrante enquanto trabalhador canavieiro. Um olhar descuidado sobre esse fenômeno pode inspirar desvios de compreensão e até preconceito como aquele que sugere ser o sertanejo homem de índole submissa.

Especialmente para os que vivem em outras regiões do Brasil, a imagem predominante do Nordeste é o da terra seca e das carcaças de animais mortos. Desfigurado, o Nordeste aparece para a cena nacional como a região que tem como característica primeira e fundamental o castigo da seca. De perto, a realidade é 
mais complexa. Além de tudo que à distância tem grande realce, na parte rural do Semiárido nordestino, de cuja realidade nos parece mais próximos os ditos e os entendimentos destacados, vamos notar a presença de uma gente que vive do árduo trabalho na terra, produzindo em pequenas e médias propriedades $\mathrm{e}$ resistindo às intempéries naturais e sociais. Falamos de milhares de agricultores cujas existências estão bem traçadas em nossos romances regionais, mas que estiveram historicamente esquecidos pelos poderes constituídos ou são alcançados precariamente pelas políticas públicas (ANDRADE 1988; SABOURIN e TRIER, 2003).

O povoamento do Nordeste sertanejo teve na atividade pecuária sua razão primeira. O gado, ocupando áreas em geral extensas de terra, "[...] foi o motor da descoberta do Sertão e do crescimento econômico" da região (CARON e HUBERT, 2003, p. 103). Os pequenos proprietários surgiram no século XVII. No começo e ainda hoje, a agricultura é apenas uma atividade secundária, ocupando pequenas áreas, destinada à produção de gêneros de subsistência e cumprindo um papel que, não fosse o caráter estratégico para a existência da região, chamaríamos de marginal.

O Semiárido alagoano ocupa o menor percentual de área inclusa no chamado 'Polígono das Secas', 43,7\%, do seu território. Por dispor de características climáticas mais favoráveis à agricultura do que as áreas semiáridas dos outros Estados nordestinos, Alagoas é "cognominado vulgarmente de 'o filé do Nordeste'" (ANDRADE, 1998, P.33).

A região sertaneja alagoana é composta por 26 municípios e nela moram cerca de 500 mil habitantes. O clima quente na maior parte do ano, em média $25^{\circ}$ C, desde os tempos coloniais, impacta a vida do sertanejo. Já o Agreste alagoano é formado por 23 municípios e tem uma população de aproximadamente $475 \mathrm{mil}$ habitantes.

Na realidade de Alagoas, a migração é um fenômeno de vulto, seja pela sua trajetória histórica, seja pelo significado econômico ou mesmo pelo fértil campo de pesquisa e análise sociológica que ele representa. A safra canavieira de 2013 deve ultrapassar os 30 milhões de toneladas e empregar aproximadamente $70 \mathrm{mil}$ canavieiros. A seca de 2012-13, fartamente noticiada pelos meios de comunicação, vem sendo considerada a maior dos últimos 50 anos. Tal fato deve contribuir para o aumento do número de migrantes para a região canavieira.

Ao migrar o camponês tem sua rotina enormemente transformada, seu corpo é submetido a uma rigorosa disciplina, sendo vigiado, bem como exigido de forma cruel. O corte da cana requer costume com o trabalho bruto, pede corpos talhados para grandes jornadas laborais. As duras jornadas de labor nos canaviais, entretanto, maltratam tanto o sertanejo habituado ao ardor do trabalho campesino quanto ao homem da região canavieira, também habituado ao trabalho bruto, porém mais reagente à exploração imposta pelo capital. A abordagem desse 


\section{Migração: a amarga vida de canavieiro do camponês do Semiárido ${ }^{1}$}

fenômeno se dará em diálogo com Michel Foucault. Na sua obra "Vigiar e Punir" encontramos categorias de análise capazes de iluminar a realidade em questão.

\section{2- Migração temporária: uma saída para os males da cerca e da seca}

A seca atual é apenas mais uma entre tantas já vividas na região do Semiárido nordestino. $\mathrm{O}$ cruzamento de dados de duas obras diferentes nos dá a dimensão dos períodos de seca na região nos três últimos séculos. Euclides da Cunha, em "Os sertões", diz que no século XVIII e XIX ocorreram dez secas. Lígia Albuquerque de Melo, no artigo "Relações de gênero na convivência com o semiárido brasileiro: a água para o consumo doméstico", registra nove secas no século XX.

Historicamente, a seca tem sido apontada como a causa da migração. Tribos indígenas que habitaram a região antes da chegada dos portugueses viam-se permanentemente obrigadas a migrar por causa das secas. Os colonizadores portugueses foram forçados a vários recuos por razão das secas até a ocupação efetiva do "Nordeste interior" (ANDRADE, 2010). O campesinato que se formou na região não teve a mesma mobilidade que os primeiros habitantes, mas nem sempre foi possível conviver com as intempéries da natureza.

Entretanto, nos dias atuais, não é a seca determinante do processo migratório, ela é uma razão secundária e assim deve ser considerada. A má distribuição das terras é o principal motivo da migração (ALMEIDA, 2010). A migração não ocorre por razões conjunturais, a seca, mas por razões estruturais, representadas pelo monopólio da terra. Como bem diz a sabedoria popular na região: o problema não é de seca, é de cerca. De forma mais ampla, conforme Francisco de Oliveira, (19881), estamos diante de uma realidade em que o capital hegemônico historicamente configura as regiões e estabelece, conforme os seus interesses, o papel de cada uma no panorama de acumulação e expropriação da natureza e do trabalho humano.

O fenômeno da migração temporária no Nordeste brasileiro remonta ao fim do século XIX e começo do século XX. Os movimentos migratórios acontecem na direção da Zona da Mata, mas também para capitais e até para outras regiões do País. Migram os pobres e, destacadamente, os mais jovens. Os proprietários rurais de unidades produtivas de pequeno e médio porte e seus filhos formam a massa migrante. Os grandes proprietários são beneficiados por esse processo. Maria Aparecida de Moraes Silva, em Retirantes do fim do século, nos diz que "[...] a migração, quer seja definitiva ou sazonal, produz a passagem de uma estrutura de dominação para outra, [...] a migração não liberta o camponês das amarras do poder dos grandes proprietários" (SILVA, 1999, p. 237).

O processo migratório é determinado por causas macroeconômicas, o que não anula o papel de indivíduos e grupos na elaboração de seus projetos 
migratórios. É o que fazem milhares de camponeses todos os anos: confrontam o caráter totalizante do capital, constroem e reconstroem as suas estratégias de reprodução. O campesinato é portador de um ethos particular, cujos códigos de produção e de convivência social contrariam as lógicas gerais do capital. Entre outras coisas, o trabalho familiar constitui a principal força de reprodução da unidade produtiva.

Há situações em que a migração garante a sobrevivência de muitas famílias camponesas durante uma parte do ano, é fonte regular de renda, de estabilidade e de redução de riscos (CARON, 2003, p. 93). Noutros casos, ela ganha contornos menos dramáticos, corresponde a uma atitude estratégica de fortalecimento das unidades produtivas. Assim constituída, a migração temporária representa não apenas um meio de sobrevivência, é uma estratégia para garantir e aprimorar a sua existência na terra de diversas famílias camponesas. De qualquer forma, ainda que seja uma necessidade, a migração não representa a incapacidade da agricultura camponesa de produzir os meios de sua reprodução, é um indicador de sua insuficiência, fato comum numa realidade que, conforme dados do IBGE (2010), $80 \%$ das propriedades rurais são minifúndios.

Dois grupos principais migram: 1 - Os desempregados do campo e da cidade - maioria dos migrantes. São trabalhadores rurais, ex-camponeses ou não, com vida no campo ou na cidade. Esse grupo, quando tem oportunidade, sobrevive do trabalho que realiza nas médias e grandes propriedades da região. No verão, migram em busca de trabalho e de melhores rendimentos. São os vínculos familiares e a identidade que têm com a região que os trás de volta. Os rendimentos obtidos no corte da cana são, muitas vezes, a única renda que têm durante o ano e, quando somadas duas safras, adquirem o direito ao seguro desemprego, ou seja, a cada dois anos, garantem um ano inteiro com salário. 2 Os camponeses com pouca terra. Sem ou com pouca tecnologia e assistência técnica, produzem para a reprodução da unidade familiar e destinam pequena margem da produção para o mercado. Atuam no limite das suas possibilidades objetivas. Têm profunda relação com a terra e forte identidade com a região. Nessas condições, a migração temporária é uma exigência de sobrevivência e uma estratégia de melhoramento da sua "condição camponesa".

Diversos são os significados do fenômeno migratório. No âmbito do lugar de moradia do migrante, determinado por condições sócio-históricas que o empurram para fora de sua unidade produtiva, a família camponesa, locus privilegiado de análise, é impactada e sofre com a migração de um ou mais dos seus membros. Entre outras coisas, os papéis cumpridos pelos membros da família que ficam são redefinidos e as afetividades de mulheres, jovens e crianças são atingidas. Conforme Menezes (2002, p. 20), "A migração masculina é parte da organização familiar e indissociável do trabalho da mulher na terra e sua responsabilidade pelo 


\section{Migração: a amarga vida de canavieiro do camponês do Semiárido ${ }^{1}$}

trabalho doméstico, socialização de crianças e reprodução dos novos trabalhadores".

Vivendo como migrado, no universo canavieiro, o migrante se depara com condições de existência extremamente adversas e com relações de produção típicas de um modelo de assalariamento, destacam-se também as crescentes contradições de classe que envolvem o mundo do trabalho, assim como são constituídas as relações de tensão com as populações locais (ALBUQUERQUE, 2009; WANDERLEY, 1979; ANDRADE, 1994;).

No universo canavieiro alagoano, de forma genérica, todo migrante do Semiárido é chamado de "sertanejo". Os 'sertanejos', por sua vez, chamam os canavieiros da Zona da Mata de os "da rua" (PLANCHEREL; ALBUQUERQUE; VERÇOSA, 2009). Quando os "da rua" caracterizam os migrantes do Semiárido de 'sertanejos', demonstram não uma incapacidade de distinguir quem é do Sertão e quem é do Agreste. Na verdade, estão demonstrando a sua rejeição contra aqueles que chegam e ameaçam os seus empregos, contra aqueles que, conforme expressam, 'aceitam' os extremos rigores e os abusos das usinas. "Eles são considerados passivos, submissos e inconscientes e, portanto, constituem-se como categoria avessa à organização de classe" (MENEZES, 2002, p. 18).

Godoi (1999, p. 70), analisando a migração de comunidades rurais do Sertão do Piauí constata que

A migração tem um caráter claro: garantir a reprodução simples da unidade camponesa, mantendo um vínculo estável com a terra, e, assim, evitar a 'reprodução negativa' [...] ou seja, menos terra para mais gente, forçando a minifundização a limites que comprometeriam a reprodução camponesa da área.

No contexto alagoano, esse fenômeno, circunscrito no âmbito da pluriatividade (CARNEIRO, 1998, SCHNEIDER, 2009), transforma o trabalhador num sujeito de dupla atividade: uma camponesa, agricultora e outra canavieira, agricultora e assalariada. Como camponês, o trabalhador é dono de um pedaço de terra, dos instrumentos de produção e dos bens produzidos por ele e por seus familiares. Essa atividade atende às suas necessidades de reprodução e é - quando é - destinada ao mercado local e regional. Enquanto canavieiro, ele é proletarizado pela moderna indústria açucareira, produz para um mercado distante e, muitas vezes, nem sabe quem é o dono da empresa para a qual trabalha.

Essa dupla condição, dada a sua regularidade e a sua ocorrência por diversos anos e por várias gerações, nos diz que tal migrante não é apenas camponês, é também canavieiro. Entretanto, apesar de ser proletarizado durante um período do ano e uma parte da sua vida, ele não é um proletário, é um 
camponês. O trabalho no canavial visa garantir e fortalecer a sua "condição camponesa", categoria desenvolvida por Van der Ploeg, cujas características incluem "um projeto de sobrevivência e resistência ligado à reprodução familiar" e a "pluriatividade" (SABOURIN, 2009, p. 32). Nesses termos, hipoteticamente, ainda que a atividade canavieira represente a principal fonte de renda da família de algum migrante camponês no período de um ano, o trabalho como canavieiro tem apenas caráter complementar. A migração pode ser uma estratégia utilizada por membros de "[...] famílias de grande porte, frequentemente polinucleares, quando o trabalho agrícola não é capaz de ocupar todos os membros de maneira contínua nem de suprir as necessidades de consumo de todos" (CARON, 2003, p. 93). Ou como nos diz Wanderley (2009, p. 14), “O que está em jogo é a sobrevivência da família pela construção/reprodução do patrimônio possível, no presente e no futuro, e da própria comunidade camponesa".

É papel fundamental da migração capitalizar as famílias camponesas para enfrentar dificuldades financeiras momentâneas e para formar poupança para investimentos futuros que fortaleçam a unidade produtiva, inclusive para adquirir bens para a propriedade ou mesmo novas terras. A migração não é um fenômeno de relevo apenas econômico, porque fortalece a pequena propriedade, implementa a agricultura camponesa e previne o avanço do latifúndio, ela afirma o campesinato como ator coletivo capaz de resistir aos modelos hegemônicos presididos pelo grande capital.

Para definir esse processo não nos parece suficientes a categoria "camponeses-trabalhadores", seja na concepção de Shanin (1970) - por este autor entender o campesinato como uma categoria marginal -, seja na concepção de Sozan (1976), que aborda o campesinato como um proletário cuja renda principal decorre do emprego não agrícola. A categoria "migrantes do trabalho", desenvolvida por Breman (1985), nos parece adequada até o momento que diz de trabalhadores que se deslocam, mas mantém os vínculos com os seus locais de origem (Menezes, 2002, p. 42-3). Diferente de Breman, entendemos que a migração temporária não transforma o camponês em proletário e nem ratifica o modo de produção capitalista, apesar de acontecer dentro dele e sob a égide de suas relações.

Um dos significados mais relevantes da migração é o impacto que ela gera em outras regiões. A região canavieira, por exemplo, há várias décadas vem recebendo migrantes no período de safra. No ensaio Cassacos e Corumbas, realizado no contexto da Zona da Mata pernambucana, Maria Teresa S. de Melo Suarez aborda a migração como parte de um processo social determinado por causas estruturais e dinâmicas produtivas diferentes. Para a autora tal relação se configura como "[...] uma forma especial de inter-relação entre a grande e a pequena propriedade (o chamado 'complexo latifúndio-minifúndio'), através da migração espacial dos trabalhadores rurais" (SUAREZ, 1977, p. 96). 


\section{Migração: a amarga vida de canavieiro do camponês do Semiárido ${ }^{1}$}

Esse movimento sempre foi povoado de conflitos e tensões. Nos últimos anos as tensões têm se renovado e assumido novos contornos. O fato é que a região canavieira vive uma transformação profunda nas últimas décadas. As relações entre capital e trabalho, especialmente, foram alteradas. Novos modelos de gestão e de controle do trabalho foram impostos, gerando dor e sofrimento para os trabalhadores canavieiros e taxas de mais-valia ainda mais agressivas (ALBUQUERQUE, 2009; CARVALHO, 2000; SILVA, 1999). Tais alterações acirraram as lutas de classes no universo canavieiro, fato que fica evidenciado com as recentes greves e protestos no universo canavieiro alagoano (CÂNDIDO; MALAGODI, 2007) e fortaleceram o interesse dos empregadores de ter a mão de obra dos migrantes 'sertanejos'. Mas eles são buscados cada vez em menor número, o corte da cana adota princípios de racionalidade produtiva típicos da administração moderna, o que significa, entre outras coisas, em redução de mão de obra e aumento de produtividade. Entretanto, o tradicional sentido estratégico utilizado pelo capital açucareiro para buscar o trabalho migrante, garantir a plena ocupação das vagas de trabalho no período da safra, está mantido.

O migrante é um corpo estranho na realidade que o recebe. Embora Hasse (2007, p.77), sentencie que "[...] para se fixar num território novo, ainda que temporariamente, o migrante precisa manter uma boa relação com o meio ambiente, nele incluídos os humanos já estabelecidos", não é isso o que tem acontecido. As relações de convivência são difíceis. Na raiz das tensões está o fato de que a presença do migrante "quebra o status quo do lugar onde se insere" (Ibidem, 78).

O 'sertanejo', como um de 'fora', um outsider, sente o olhar de preconceito e de discriminação contra si e contra a sua região, ressente-se, é visto como um desgarrado da sua região, da sua gente e da sua família, mas, é principalmente a sua condição de concorrente no mundo do trabalho, que faz com que seja visto como um intruso, uma ameaça, despertando o olhar hostil dos demais trabalhadores canavieiros. A fama de bom trabalhador representa a grande vantagem dos 'sertanejos' em relação aos 'da rua'.

As representações produzidas pelos trabalhadores "da rua" e pelos patrões constituem identidades distorcidas do 'sertanejo'. Ser 'sertanejo' é a sua "imperfeição original", em seguida lhes são imputados imperfeições e atributos que o descaracterizam como ser humano comum, diverso, dinâmico. Ser 'sertanejo' ganha fortes contornos negativos, configurando-se como um estigma (GOFFMAN, 2008, p. 15) e confirmando a tese de que "ninguém migra impunemente" (Hasse, 2007, p. 84). De um lado, ele aparece como desprovido de autoestima e de consciência de classe, é acusado de tolerar os abusos extremos dos patrões; do outro, ele é máquina, dócil, pois além de cumprir as rigorosas metas de produção, convive com condições que lhes são hostis. 
Por sua vez, o camponês que migra para a região canavieira tem uma condição que os 'da rua' não conhecem. Ele tem uma atividade de autoreprodução, o que inclui um pedaço de terra, uma casa própria e algum gado, por isso, não raro, lançam um olhar superior, enxergam os 'da rua' como trabalhadores em condições de inferioridade financeira e patrimonial. Os 'da rua', muitas vezes, sequer têm um lugar próprio para morar, vivem de aluguel nos povoados, vilas ou mesmo nas periferias da cidade. Enquanto isso, o camponês move-se em função de um projeto de manutenção e/ou de aprimoramento do patrimônio que possui, o que o faz, consequentemente, um sujeito com mais autonomia (CASTORIADIS, 1982; SADER, 1988).

\section{3- A disciplina e o trabalho no canavial}

Michel Foucault (1975) nos mostra que historicamente a disciplina é tema obrigatório na vida de diversas instituições e que ela cumpre papel organizador em múltiplos processos sociais. A disciplina é instrumento de poder e se estende sobre os corpos, as mentes, o tempo e os fluxos deles dependentes ou decorrentes. Nas relações de produção de bens e mercadorias, a disciplina do corpo e o controle do tempo são movimentos combinados. É parte do bom desempenho da administração moderna submeter os dois. $\mathrm{O}$ aumento da produção exige que $\mathrm{o}$ tempo seja gerenciado e que o corpo seja treinado a adotar ritmos cada vez mais enérgicos.

A administração moderna é uma criação científica subordinada ao capital e tem como fito aprimorar a exploração do homem e da natureza, maximizando lucros. Esse processo é parte de um movimento de racionalização que caminha em diferentes sentidos. Na indústria, um conjunto de mudanças circunscritas ao fenômeno da reestruturação produtiva impõe grandes mudanças no processo produtivo e lega ao trabalho um lugar de graves precariedades. No campo, o mesmo fenômeno tem feito estragos ainda maiores. Tradicionais relações de produção têm sido alteradas e novas dinâmicas de concentração de terra são observadas. São parâmetros importantes nesse processo o controle técnicocientífico da mão de obra, o gerenciamento do tempo e o aumento da produção. Os modelos produtivos da indústria moderna têm sido aperfeiçoados e estendidos ao campo. Essas mudanças decorrem de uma ação articulada do empresariado e do Estado. Conforme Maria Aparecida de Moraes Silva, "A partir dos anos 50, o aumento da produção agrícola vai ocupar o centro do discurso das classes dominantes por meio da ideologia desenvolvimentista que condenava o atraso do campo, a fraca produtividade, os métodos atrasados e a miséria dos trabalhadores" (SILVA, 1999, p. 62).

Os controles e os rigores experimentados na indústria têm provocado mudanças profundas nas relações de produção do campo. No corte da cana, por 
Migração: a amarga vida de canavieiro do camponês do Semiárido ${ }^{1}$

exemplo, a adoção dos gabaritos produtivos da indústria tem impactado gravemente o corpo, provocado adoecimentos vários e até óbitos (SILVA, 1999, 2006). Nem todo mundo suporta as atuais exigências para o trabalho no corte da cana. As mulheres foram as primeiras a ser dispensadas. Em seguida, foram afastados os homens mais velhos. As seleções primam por homens com mais de 18 anos e menos de 40 (SANTOS, 2012; ALBUQUERQUE, 2009; MENEZES, 2002). Raramente são contratados os que estão fora desse perfil. É mais fácil contratar alguém que não tenha experiência com o corte da cana do que alguém que ultrapasse a fronteira etária dos 45 anos. Força e disciplina precedem a técnica. No caso do migrante sertanejo, desde o recrutamento, já são observados tais critérios. Migram para o corte da cana os pobres, mas só os mais jovens e mais aptos são contratados (SILVA, 2006; CARON, 2003; ANDRADE, 1988).

O migrante do Semiárido não precisa 'expulsar o camponês' para fazer surgir a 'fisionomia de cortador de cana', apenas, no começo, é necessário discipliná-lo, adaptá-lo ao novo ambiente, aos movimentos e às exigências do novo trabalho. Entretanto, como a migração é cíclica, logo seus corpos são docilizados. Conforme Foucault (1975, p, 126), dócil é "um corpo que pode ser submetido, que pode ser utilizado, que pode ser transformado e aperfeiçoado".

A disciplinarização dos corpos tem no estabelecimento de horários rígidos de trabalho um componente fundamental. O canavieiro sai para o trabalho com os primeiros raios de sol e volta para o alojamento no final do dia. Considerando o tempo gasto com o deslocamento, os dias de trabalho duram cerca de doze horas. Considerando, ainda, que o trabalhador não tem autonomia para decidir a hora de saída para o trabalho e que também não define a hora que retorna do serviço, constatamos que ele perde o controle sobre o seu corpo durante a maior parte do dia.

Os camponeses migrantes vivem em alojamentos ou em casas alugadas pelas usinas. O mais comum é que fiquem em alojamentos construídos distante da cidade ou de outros povoamentos, evitando os desvios de conduta e a 'contaminação' com os do lugar (ANDRADE, 1988, p. 120). Vivendo em alojamento o migrante é alguém cujo corpo pode ser melhor sujeitado, mais controlado pelo capital. O migrante que vive em alojamento é mantido "sob atenta vigilância" (MENEZES, 2002, p. 145). Enfim, "As disciplinas, [...] marcam lugares e indicam valores; garantem a obediência dos indivíduos, mas também uma melhor economia do tempo e dos gestos" (FOUCAULT, 1975, p, 135). O disciplinamento é um instrumento de controle do corpo enquanto fenômeno físico-psicológico, racional-lúdico.

A exigência de cumprimento de metas de produção, ainda que oculta no contrato de trabalho é outro dado motivador das políticas de controle dos corpos. O trabalhador que não é capaz de atingir as metas que o empregador estima como satisfatórias não terá seu contrato renovado na próxima safra. Cada trabalhador é 
observado na sua capacidade de produção diária, semanal, mensal, consolidando uma média anual de produção. A tabulação individualizada desses dados servirá de parâmetro para contratações futuras. Também é observada a regularidade produtiva de cada sujeito, se adoeceu ou não durante a safra, sua relação com os supervisores durante o corte da cana, sua capacidade de aceitar e obedecer às regras de produção e a sua convivência com o grupo. Tudo convida à disciplina, à sujeição do corpo e à submissão diante do poder.

Os supervisores e fiscais cumprem papel estratégico nesse processo. O poder de observar é designado a pessoas que monitoram o trabalhador. No passado, um empreiteiro e um cabo davam conta do trabalho de uma turma de muitos homens e muitas mulheres. Hoje, encontramos novos sujeitos, responsáveis pela medição, fiscalização e controle do trabalho. Conforme Foucault,

[...] o olhar disciplinar teve [...] necessidade de escala. É preciso decompor suas instâncias, mas para aumentar a sua função produtora. Especificar a vigilância e torná-la funcional. Vigiar torna-se então uma função definida, mas deve fazer parte integrante do processo de produção, deve duplicá-lo em todo o seu cumprimento. Um pessoal especializado torna-se indispensável, constantemente presente, e distinto dos operários. [...] A vigilância torna-se um operador econômico decisivo, na medida em que é ao mesmo tempo uma peça interna no aparelho de produção e uma engrenagem específica do poder disciplinar (FOUCAULT, 1975, pgs 156-157).

Esse "olhar disciplinar" garante a aplicação da disciplina e os resultados almejados pelas empresas, sem eles não há garantia dos fins e nem da efetivação do poder. Os atuais padrões de disciplinamento praticados nos canaviais são relativamente recentes e em grande medida estranhos ao cotidiano camponês. Eles imprimem marcas profundas no corpo e na alma campesina. Importa, portanto, investigar os 'efeitos colaterais' do disciplinamento nos canaviais no trabalho e na vida do migrante sertanejo. Eles contrastam e supera a disciplina que a experiência campesina requer, dela, por exemplo, não faz parte a perseguição de metas de produção estabelecidas por forças tão exteriores. No corte da cana o camponês experimenta uma nova disciplina, tem contato com um corpo técnico de acompanhamento, vigilância e controle da produção, é proletarizado. A experiência campesina é impactada pelo disciplinamento nos canaviais. Ainda que não seja alterada, haja vista que a sociedade e a economia campesina são de outra natureza e têm outros fins, a experiência da migração e da proletarização mexe com o fazer campesino, com a família e com o sujeito migrante. 
Migração: a amarga vida de canavieiro do camponês do Semiárido ${ }^{1}$

Pelo seu afinco no trabalho, o migrante é conhecido como um trabalhador que nunca faz "corpo mole". O trabalhador que não faz "corpo mole" é aquele que tem uma disposição destacada para o trabalho. Essa disposição no universo canavieiro é imperativa, o sistema é de produção, assim, ganha mais quem produz mais. Um exemplo da forma destacada e o empenho diferenciado dos migrantes sertanejos é que eles em geral são campeões de produção nas safras canavieiras. Nossas conversas com os agenciadores nos diz que são os sertanejos que mais ganham o prêmio "facão de ouro". Esse prêmio foi instituído por algumas alagoanas usinas e através dele são distribuídos prêmios sob a forma de motocicleta, aparelhos domésticos e dinheiro para os trabalhadores que se sobressaem como mais produtivos durante a safra. Curioso é que um agenciador disse-nos ter um sertanejo convertido o seu prêmio em cabeças de gado. Efetivamente, a migração tem para o sertanejo outras motivações.

O sentido estratégico que o camponês migrante empresta à migração sazonal é um componente essencial para entender o seu comportamento no universo canavieiro, isto ajuda a entender o mecanismo "que o torna tanto mais obediente quanto é mais útil, e inversamente" (FOUCAULT, 1975, p, 127). Este fenômeno, paradoxalmente, pode ser registrado como códigos de sujeição ou de resistência.

É certo que o migrante não detém o governo do processo migratório e que não é da sua escolha ser explorado no corte da cana. O camponês migra porque é forçado e é disciplinado no canavial porque é forçado a migrar. Entretanto, ainda que submetido a poderosos determinantes naturais e estruturais, estes determinantes não são capazes de deslocar as relações de poder para um único polo, bem como não são capazes de impedir que sujeitos individuais e coletivos articulem racionalmente as suas ações e projetem as próprias existências e nem que teçam sonhos de uma nova realidade.

Os camponeses migrantes são movidos por duas razões muito pragmáticas: 1) a busca do maior rendimento pelo trabalho desenvolvido para garantir a sua reprodução e a da sua família, assim como todo trabalhador assalariado, 2) a procura das melhores condições para a realização de uma poupança que garanta a manutenção e o aprimoramento de sua propriedade. As ações disciplinadoras que favoreçam tais fins podem até ser bem vistas pelos camponeses, ainda que em certas circunstâncias estas lhes imponham maior esforço físico, são entendidas como 'males necessários'. Da mesma forma, qualquer iniciativa que contrarie seus fins é alvo de reações, um exemplo disso foi a adoção de contratos safristas por diversas usinas alagoanas em 2011. Essa medida impossibilitava a soma um ano de carteira assinada a cada duas safras e lhes impediam de receber o benefício do seguro desemprego bienalmente. Diante do prejuízo, os migrantes fizeram greve. Esse fato foi inédito e ajudou a reverter a decisão das usinas. Atualmente, a certeza do seguro desemprego a cada duas safras é uma das maiores razões da migração. 
O disciplinamento do corpo e o controle do tempo são instrumentos que determinam a produção. Os corpos sentem e expressam as conseqüências disso. Aos quarenta anos, por exemplo, o trabalhador canavieiro aprimorou a técnica do corte da cana, mas suas energias estão reduzidas e sua capacidade de produção comprometida. Os desgastes físicos decorrentes do esforço repetitivo e da exigência de ter grande produção afetam física e psicologicamente o trabalhador. É comum encontramos canavieiros incapacitados para o trabalho após algumas safras.

A preferência dos usineiros pelo trabalhador sertanejo decorre do fato do controle sobre ele ser mais efetivo, ocorrendo até nos horários de folga. Um fato exemplar desse controle pode ser demonstrado pelas faltas nos dias de segundafeira ao trabalho, uma tradição na região canavieira de Alagoas. Os moradores dos povoados e 'da rua' faltam com alguma freqüência ao trabalho no primeiro dia da semana, o sertanejo não, tem maior regularidade. Segundo os responsáveis pela freqüência, os 'da rua' costumam ir a festas no domingo, "queimando" o dia seguinte de trabalho.

O migrante sertanejo é considerado pelos empregadores como um bom cortador de cana. O bom cortador de cana é apenas aquele que tem maior tenacidade física e que é capaz de produzir em grande quantidade, mas que o faz cuidando dos detalhes. Como bem diz Foucault (1975, p, 128), “A disciplina é uma anatomia política do detalhe". Uma das grandes mudanças introduzidas nos eitos foi a adoção de técnicas de produção marcadas por um conjunto minucioso de procedimentos. A rigorosa especificação do tamanho do 'toco' da cana, a severa separação do 'olho' cortado da cana da esteira, a rígida disposição da cana cortada nas esteiras e outras práticas, exigiu um disciplinamento maior dos trabalhadores e um acompanhamento permanente dos fiscais. A lógica que preside tais mudanças é determinada pelo capital em seu processo mundial de reestruturação produtiva e visa combinar quantidade e qualidade produtiva, reduzir custos e ampliar lucros, o que demanda, entre outras coisas, a existência de corpos e mentes bem disciplinados.

Essas mudanças interferem muito na dinâmica histórica de produção dos canavieiros e nas relações sociais que os envolve. Não que antes não existisse vigilância e acompanhamento, mas o novo modelo segue um conjunto de procedimentos técnico-científicos para o qual

Importa estabelecer as presenças e as ausências, saber onde e como encontrar os indivíduos, instaurar comunicações úteis, interromper as outras, poder a cada instante vigiar o comportamento de cada um, apreciá-lo, sancioná-lo, medir as qualidades ou os méritos. Procedimento, portanto, para conhecer, dominar, utilizar. 
Migração: a amarga vida de canavieiro do camponês do Semiárido ${ }^{1}$

A disciplina organiza um espaço analítico (FOUCAULT, 1975, p. 130).

Segundo Foucault (1975, p, 139), “Um corpo disciplinado é a base de um gesto eficiente". Os trabalhadores que não alcançam os padrões de eficiência exigidos são punidos. Ao passo que retalia a ineficiência, a punição reafirma os padrões exigidos e ordena o sujeito punido. O poder de punir é exclusivo do empregador, representado por seus fiscais. A fiscalização da qualidade do trabalho é cada vez mais rigorosa. As técnicas e regras de corte da cana são sedimentadas entre os trabalhadores e condicionam o apontamento da tarefa ou a sua anulação. A avaliação do trabalho é diária e pautada por procedimentos objetivos, por regras bem definidas, mas também estão presentes critérios subjetivos. Se o serviço for considerado mal feito, o trabalhador pode ser punido com o corte do dia. Entretanto, $\mathrm{O}$ corte do dia não é um expediente de punição para ser utilizado vulgarmente, nem tampouco é comum o seu uso coletivo. Punir individualmente gera menos rebuliço. A punição coletiva, além de estar sujeita a uma reação também coletiva, gera uma memória que pode ser reativada em qualquer outro momento contra o punidor. Um exemplo disso pode ser encontrado num relato reproduzido em Menezes (2002, p. 134) segundo o qual trabalhadores se negam a trabalhar com um Dr. Eraque, "miserável (...) que cortou o dia da gente na Usina São José". A aplicação de penalidades produz conflitos, os trabalhadores reagem aos prejuízos e à desvalorização social que as punições representam.

\section{4- Considerações finais}

O camponês do Semiárido alagoano não tem como viver apenas da produção que realiza na sua terra, ela é insuficiente e precisa ser complementada com outras rendas. A venda de dias de trabalho para um grande proprietário da região ou mesmo a realização de trabalhos como pedreiro, marceneiro ou outros, também não garante a sua e a sobrevivência da sua família. Migrar é preciso.

Ao mergulhar no mundo canavieiro, o migrante tem rompido, temporariamente, a sua condição de camponês, é precarizado. Sua força de trabalho ajuda a indústria canavieira a existir e a prosperar. Paradoxalmente, a indústria canavieira, assim como a construção civil, por exemplo, são importantes para a manutenção de milhares de pequenas propriedades agrícolas no Semiárido alagoano e de todo o Nordeste. Essa relação de complementaridade é perversa, pois acontece em condições desiguais.

As transformações ocorridas na dinâmica de produção canavieira têm agravado ainda mais as condições de vida dos migrantes e do conjunto dos trabalhadores canavieiros. Metas rigorosas de produção e padrões produtivos cada vez exigentes têm feito crescer o número de mortes por exaustão e adoecimentos 
diversos acometem os canavieiros submetidos a ritmos de trabalho intensos. O campesinato migrante assume esforços físicos ainda mais graves. $\mathrm{O}$ seu projeto de fazer poupança tem efeito negativo sobre o seu corpo como canavieiro e favorece os donos do capital que se aproveitam disso para aprimorar os mecanismos de exploração do trabalhador.

Submetido à gana voraz do capital sucroalcooleiro o camponês tem o seu corpo maltratado e o tempo de sua vida monitorado pela disciplina produtiva inspirada em conteúdos técnico-científicos cada vez mais elaborados. A essa realidade ele procura adaptar-se, e assim, é constituída "uma relação de docilidade-utilidade" (FOUCAULT, 1975, p, 126). Essa relação de "docilidadeutilidade" não representa um nexo de heteronomia e de poder unilateral absoluto. Dominação e resistência compõem um fruto agridoce. Estamos diante dele. Anômalo na natureza, estranho e quase imperceptível na realidade. Na dominação do migrante há uma dimensão de deixar-se domar quando é útil e vantajoso.

Uma das razões dos conflitos entre os 'da rua' e os 'sertanejos' nos últimos anos tem sido a não adesão dos mesmos nos movimentos grevistas ocorridos na região. Só em 2010 foram registradas 14 greves de canavieiros em Alagoas. O motivo principal foi a adoção do contrato safrista, expediente implementado por 17 das 24 usinas. O contrato safrista, diferentemente do contrato por tempo indeterminado, isenta a usina da multa rescisória de $40 \%$ ao final da safra. Apesar de ter amparo legal, o contrato foi repudiado pelos trabalhadores que são por ele impedidos de, após duas safras, terem direito ao seguro desemprego.

Reiteradamente os 'sertanejos' foram indiferentes às lutas por melhores salários e por melhores condições de trabalho na atividade canavieira. Em, excepcionalmente, na usina Guaxuma, localizada no município de Coruripe, eclodiu uma greve de 'sertanejos'-canavieiros. Em defesa da validade da migração como estratégia de reprodução da sua condição campesina, os 'sertanejos' rebelaram-se: enfrentaram o contrato safrista. Esta não foi, como já vimos, a única greve contra o contrato, os 'da rua' já vinham enfrentando tal imposição das usinas, mas, por ter sido desencadeada, liderada e conduzida unicamente por 'sertanejos' - os 'da rua' ficaram indiferentes a esta greve -, ela teve significados particulares. O primeiro a ser constato: o fim do mito de que o 'sertanejo' é passivo e tolera qualquer abuso. $O$ contrato safrista feria os seus interesses mais estratégicos. Outros significados serão revelados.

Diz-nos Foucault (1975, p, 28), que “a necessidade é também um instrumento político cuidadosamente organizado, calculado e utilizado" para o disciplinamento do corpo. Entretanto, devemos complementar dizendo que sobre a necessidade também atua quem necessita. $\mathrm{O}$ portador da necessidade, ainda que numa faixa menor de ação, faz seus cálculos, organiza os seus atos e os seus comportamentos a partir da necessidade que tem e para além dela. Vontades e desejos inspiram resistência e autonomia. Não entender que o camponês atura um 
Migração: a amarga vida de canavieiro do camponês do Semiárido ${ }^{1}$

domínio maior do que o 'da rua' é um erro tão elementar quanto pensar que ele pode migrar e não ser submetido à disciplina laboral imposta pelos novos ditames do capital sucroalcooleiro. Esse fenômeno é complexo, já motivou muitos estudos e continua aberto a investigações. Instigam-nos os significados físicos e psicológicos dos novos padrões disciplinares sobre o sujeito migrante, mas principalmente os impactos sobre a sua família e a sua existência campesina.

Sem dúvidas, o camponês migra porque precisa migrar. A migração temporária, entretanto, é mais do que uma exigência da realidade, ela assume contornos de uma atividade pluriativa, complementar, alternativa, é parte das estratégias de reprodução do campesinato. Forçado pela realidade, mas também em nome da manutenção da pequena propriedade e da autonomia relativa que ela representa, o camponês tanto faz trabalhos pontuais na sua região como migra durante os períodos de estiagem.

É a compreensão do caráter contraditório e dialético dessa realidade que nos permite entender os significados da migração na experiência do campesinato. No Brasil, desde o período colonial, a capacidade do campesinato de resistir à hegemonia bruta do grande capital escapa às visões lineares da história. A resistência campesina é um fenômeno duradouro. Contrariando aos deterministas, o campesinato não está em liquidação e nem vive um processo inexorável de proletarização. Nada mais fátuo do que tratá-lo como categoria pretérita e a sua existência como fenômeno residual no conjunto da sociedade moderna.

Por fim, a migração é objeto de diversas áreas de estudo. Conhecimentos produzidos por pesquisadores da sociologia, da história, da antropologia, da demografia e da geografia, por exemplo, são imprescindíveis e complementares para a compreensão da questão. $\mathrm{O}$ fenômeno da migração está inserido num conjunto de relações econômicas, sociais, políticas e culturais que são indissociáveis. Não é possível conhecer adequadamente o fenômeno migratório sem o diálogo entre os saberes das diversas áreas de estudo e sem compreender que sobre ele implicam diferentes motivações. O método crítico-dialético nos indica os meios fundamentais para a realização das tarefas de pesquisa que despontam e para o entendimento das dinâmicas contraditórias da realidade.

Ainda são poucos os estudos dedicados a esses temas em Alagoas. É importante continuar pesquisando a realidade do Semiárido, a migração campesina para o trabalho no corte da cana e as transformações ocorridas no universo canavieiro. Urge a formação de uma nova geração de pesquisadores dedicada à pesquisa de Alagoas. No momento, o grupo de pesquisa Trabalho e Capitalismo Contemporâneo, a Rede de Pesquisadores e o Núcleo de Estudos do Semiárido Alagoano (NESAL), são espaços promissores que devem ser fortalecidos. 
Cícero Ferreira de Albuquerque

Márcio de Matos Canielo

\section{5- Referências bibliográficas}

ALBUQUERQUE, Cícero Ferreira de. Cana, casa e poder. Maceió: Edufal, 2009. ALMEIDA, Sávio. Manuel Correia de Andrade: os empobrecidos e a terra. In. Economia política do desenvolvimento: Revista de Ciências Econômicas da Faculdade de Economia, Administração e Contabilidade - UFAL. - V. 3, Edição especial - 224p. - Maceió: CEPAL/UFAL, ago. 2010.

ANDRADE, Manuel Correia de. Modernização e pobreza: a expansão da agroindústria canavieira e seu impacto ecológico. São Paulo: Ed. da Universidade Estadual Paulista, 1994.

. A Terra e o homem no Nordeste: contribuição ao estudo da questão agrária no Nordeste. 6. ed. Recife: Editora Universitária da UFPE, 1998.

ANDRADE, Lopes. Introdução à sociologia da seca. Fortaleza: Banco do Nordeste, 2010.

CÂNDIDO, Paulo e MALAGODI, Edgard. Mobilização de trabalhadores canavieiros e ação estatal no setor sucroalcooleiro do Nordeste. Cadernos de Ciências Sociais Aplicadas do Núcleo de Estudos e Pesquisas em Ciências Sociais Aplicadas (Nepaad). Departamento de Ciências Sociais (DCSA). Universidade Estadual da Bahia (UESB). Ano VII, no 08, jul./dez. 2009. Vitória da Conquista: edições da UESB, 2009.

CARNEIRO, Maria José. Camponeses, agricultores e pluriatividade. Rio de Janeiro: Contra Capa Livraria, 1998.

CARON, Patrick; SABOURIN, Eric. Camponeses do Sertão: mutação das agriculturas familiares no Nordeste do Brasil. Brasília, DF: Embrapa Informação Tecnológica, 2003.

Diversidades e trajetórias de evolução das unidades produtivas. In. CARON, PATRICK; SABOURIN, Eric. Camponeses do Sertão: mutação das agriculturas familiares no Nordeste do Brasil. Brasília, DF: Embrapa Informação Tecnológica, 2003.

CARON, Patrick; HUBERT, Bernard. Dinâmicas do Sistema de Pecuária. In: CARON, Patrick; SABOURIN, Eric. Camponeses do Sertão: mutação das agriculturas familiares no Nordeste do Brasil. Brasília, DF: Embrapa Informação Tecnológica, 2003.

CASTORIADIS, Cornelius. A instituição imaginária da sociedade. Rio de Janeiro: Paz e Terra. 1982.

CARVALHO. Cícero Péricles de. Análise da reestruturação produtiva da agroindústria sucro-alcooleira alagoana. Maceió: Edufal, 2000.

GODOI, Emília Pietrafesa de. O trabalho da memória: cotidiano e história no Sertão do Piauí. Campinas, SP: Editora da Unicamp, 1999. 


\section{Migração: a amarga vida de canavieiro do camponês do Semiárido ${ }^{1}$}

GOFFMAN, Erving. Estigma: notas sobre a manipulação da identidade deteriorada. Rio de Janeiro: LTC, 2008.

GARCIA JR, Afrânio; HEREDIA, Beatriz Alasia de. Reconversões identitárias, mobilidade e campesinato. In: GODOI, Emilia Pietrafesa, MENEZES, Maria Aparecida de, MARIN, Rosa Acevedo (Org.). Diversidade do campesinato: expressões e categorias. São Paulo: Editora UNESP; Brasília, DF: Núcleo de Estudos Agrários e Desenvolvimento Rural, 2009.

HASSE, Geraldo. "Meus caros pais": uma trajetória migrante. In. CUNHA, Maria Jandira Cavalcanti... [et al.]. Migração e identidade: olhares sobre o tema. São Paulo: Centauro, 2007.

HEREDIA, Beatriz Alasia de. Formas de dominação e espaço social: a modernização da agroindústria canavieira em Alagoas. São Paulo: MCT/CNPq/Marco Zero, 1988. IBGE. Censo Demográfico - 2010. Rio de Janeiro: IBGE, 2010.

MELLO, Paulo Décio de Arruda. Cana-de-açúcar e Reestruturação Produtiva: ação sindical e dos movimentos sociais rurais em Alagoas a partir de 1985. $256 \mathrm{f}$. Tese (Doutorado em Sociologia) Universidade Federal de Pernambuco Recife, 2002. MENEZES, Marilda Aparecida de. Redes e enredos nas trilhas dos migrantes: um estudo de famílias de camponeses migrantes. Rio de Janeiro: Relume Dumara, 2002.

OLIVEIRA, Chico. Elegia para uma re(li)gião. Rio de Janeiro, Paz e Terra, 1981. PLANCHEREL, Alice Anabuki ALBUQUERQUE, Cícero Ferreira de; VERÇOZA, Lúcio Vasconcellos de. Os sertanejos e "os da rua": Idas e vindas do trabalho nos canaviais alagoanos. In: Anais do I Seminário Internacional Ruralidades, Trabalho e Meio Ambiente, São Carlos (UFSCar), 2011.

SABOURIN, Eric.; TRIER, Rémi. Manejo de água em sistema pluvial sequeiro. In: CARON, Patrick; SABOURIN, Eric. Camponeses do Sertão: mutação das agriculturas familiares no Nordeste do Brasil. Brasília, DF: Embrapa Informação Tecnológica, 2003.

SABOURIN, Eric. Camponeses do Brasil: entre a troca mercantil e a reciprocidade. Rio de Janeiro: Garamond, 2009.

SANTOS, Charles dos. Trabalho e adoecimento nos canaviais alagoanos: o caso dos irrigantes e operadores de herbicida. In: SEMINARIO DE SAÚDE DO

TRABALHADOR DE FRANCA, 8., 2012, Franca. Proceedings online. Unesp, Franca, Available from:

$<$ http://www.proceedings.scielo.br/scielo.php?script=sci_arttext\&pid=MSC0000000 112012000100040\&lng=en\&nrm=abn>. Acess on: 01 Fev. 2013.

SCHNEIDER, Sérgio. A pluriatividade na agricultura familiar. Porto Alegre: Editora da UFRGS, 2009.

SADER, Eder. Quando novos personagens entraram em cena. Rio: Paz e Terra, 1988. SILVA, Maria Aparecida de Moraes - Errantes do fim do século. São Paulo: Fundação da Editora da UNESP, 1999. 
Cícero Ferreira de Albuquerque

Márcio de Matos Canielo

A morte ronda os canaviais paulistas. Reforma Agrária - Revista da Associação Brasileira de Reforma Agrária, São Paulo, v. 33, no 2, p. 111-142, 2006.

SUAREZ, Maria Teresa Sales de Melo. Cassacos e corumbas. São Paulo, Ática, 1977. WANDERLEY, Maria de Narareth B. Capital e propriedade fundiária na agricultura brasileira. Rio de Janeiro: Paz e Terra, 1979.

Prefácio à edição brasileira. In. SABOURIN, Eric. Camponeses do Brasil: entre a troca mercantil e a reciprocidade. Rio de Janeiro: Garamond, 2009. 